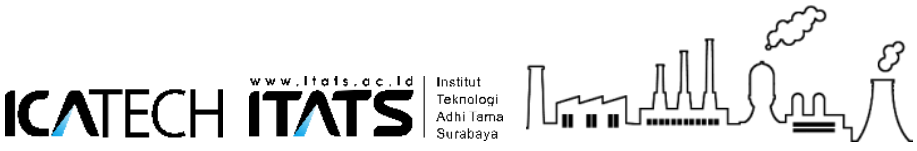

The $1^{\text {st }}$ International Conference on Advanced Engineering and Technology - 2018

\section{A Review of Structural Relationships in Closed-Loop Supply Chain Model}

\author{
E Yuliawati1,3, Pratikto1, Sugiono2 and O Novareza2 \\ 1Department of Mechanical Engineering, Faculty of Engineering, Universitas Brawijaya, Indonesia \\ 2Department of Industrial Engineering, Faculty of Engineering, Universitas Brawijaya, Indonesia \\ 3Department of Industrial Engineering, Faculty of Industrial Technology, Institut Teknologi Adhi Tama \\ Surabaya, Indonesia \\ eviyulia103@gmail.com
}

\begin{abstract}
The acquisition strategy of returned products has become essential in the study of reverse supply chain. There are three primary activities included in the process of a the reverse supply chain, the acquisition of returned products, the remanufacturing process, and redistribution. This literature review intends to study the existing relationship amongst supply chain players in a closed-loop supply chain (CLSC) model. In the remanufacturing process performed by the company, returned products must be collected from consumers. Therefore, remanufacturing companies rely upon consumers as cores suppliers. This makes the good relationship between the two become crucial in company operational sustainability successfully. In this study, the identified journal articles were categorized into types of structural relationships between supply chain players and network structures of a reverse supply chain. Types of structural relationships are ownership-based, service-contract, directorder, deposit-based, credit-based, buy-back, and voluntary-based. There are four types of returned product collector and remanufacturer: Original Equipment Manufacturer (OEM), a third party (3PL), retailer, and remanufacturer. Discussion of the journal articles was presented in each category. After that, the structural relationship was explored to find its advantage and disadvantage, so that CLSC can be managed effectively and efficiently. As a summary, suggestions for future research were described as the result of the literature review conducted.
\end{abstract}

\section{Introduction}

Reverse Logistics (RL) and CLSC have been in the spotlight for the past few years. This is related to the increased concern of the government, organizations, and individuals in addressing environmental impacts due to climate change and global warming, production process, and consumption activities. Environmental, economic and social issues arise as motivation in the development of the concept. Reverse flow has to be designed as good as a forward flow to attain an effective and efficient CLSC process. The general scheme of material flow in a CLSC process is described in Figure 1. 


\section{ICATECH ITAT'S =}

The $1^{\text {st }}$ International Conference on Advanced Engineering and Technology - 2018

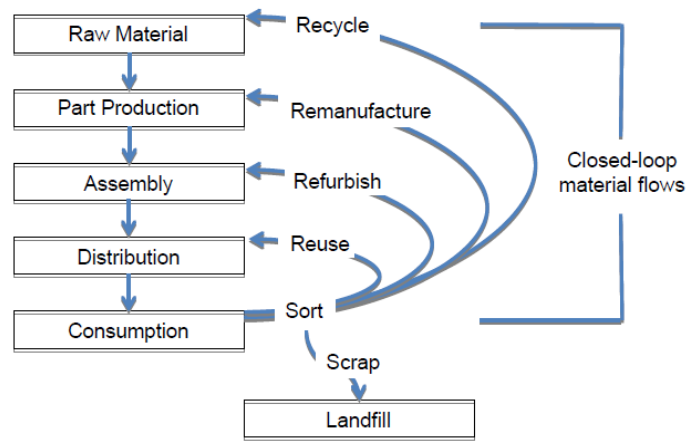

Figure 1. CLSC material flows [1]

One of the challenges in CLSC process is regarding to the availability of cores, the raw materials used in the remanufacturing process. According to Ostlin, Sundin, \& Bjorkman [2]; Sundin \& Dunback [3]; Ferguson \& Toktay [4] these challenges are especially the ones concerning core quantity and quality, as well as timing. The occurrence of problems surrounding the availability of cores can be seen from three different perspectives: consumer, remanufacturer, and returned product. The relationship between remanufacturer and consumer as a core supplier plays a role in problems related to cores acquisition. According to Ostlin, Sundin, \& Bjorkman [2], there are seven types of structural relationship which help companies to control the process of collecting returned products, between manufacturer and consumer as core supplier: (1) Ownership-Based, (2) Service-Contract, (3) DirectOrder, (4) Deposit-Based, (5) Credit-Based, (6) Buy-Back and (7) Voluntary-Based.

A literature review is a process of presenting a spesific topic of study in detail by studying and exploring relevant journal articles to find a gap for future research. The result from a literature review must be able to initiate a further study of the topic. The review of RL/CLSC topic has been conducted by Govindan, Soleimani \& Kannan [5]. It classified papers in four classes: RL, CLSC, sustainable and green. The result shows that there are 16 research areas in RL/CLSC. The three most explored areas are designing and planning, survey, and price and coordination. The classification directs to six topics available for further research. Furthermore, the review carried out by Guo et al. [6] focused on the mechanism in contracts for RL/CLSC. The review process was completed by investigating the mechanism contracts which had been applied to 50 articles. The result shows that there are nine variations of SC contracts with various leadership channels.

Unlike the previous reviews, this study classified journal articles according to the structural relationship between remanufacturer and consumers as stated by Ostlin, Sundin, \& Bjorkman [2]. The better the structural relationship management is in a company, the higher the assurance of cores availability in the remanufacturing process. As a result of adequate availability, the unbalanced returndemand will diminish. In other words, a successful remanufacturing company in managing structural relationship will eventually contribute to the success or remanufacturing business. Several researchers discussed the effectiveness of returned product acquisition strategy by means of the quantitative model. Considering how research in the area of RL/CLSC has expanded, this paper has reviewed journal articles discussing the structural relationship between and among reverse supply chain players in CLSC model. The analysis focused on the types of structural relationship applied to the model and identifying returned product collectors and remanufacturers.

\section{Research Methodology}

There are several approaches in deciding which journal articles are relevant to the literature review. In this paper, the search for reputable academic journal articles was carried out by utilizing several database references such as ScienceDirect, Proquest dan Emerald using "reverse supply chain", "closed-loop supply chain", "cores acquisition", "remanufacturing", "review", and the combinations 
as the keywords. Some of the keywords typically appear in the title, abstract, or keywords of the academic journal articles. After that, the search results were categorized into the structural relationship as stated by Ostlin, Sundin, \& Bjorkman [2]. Table 1 presents the search results according to the journal names.

Table 1. Literature Distribution by Journal Name

\begin{tabular}{|c|c|}
\hline Journal Name & References \\
\hline Kybernetes & Qiaolun, Jianhua, and Tiegang [7] \\
\hline Journal of Manufacturing Systems & Maiti and Giri [8], Giri and Sharma [9] \\
\hline Journal of Business Economics & Gonsch [10], Hahler and Fleischman [11] \\
\hline $\begin{array}{l}\text { International Journal of Production } \\
\text { Economics }\end{array}$ & $\begin{array}{l}\text { Aras, Gullu, and Yurulmez [12], Kleber, Zanoni, and } \\
\text { Zavanella [13], Wu [14], Chuang, Wang, and Zhao } \\
\text { [15], Xiong et al. [16], Wei, Tang, and Liu [17] }\end{array}$ \\
\hline Production and Operation & Bakal and Akcali [18], Galbreth and Blackburn [19], \\
\hline Management & Ferguson et al. [20] \\
\hline European Journal of Operational & Feng, Govindan, and Li [21], Teunter, Douwe, and \\
\hline Research & Flapper [22], Cai et al. [23] \\
\hline Journal of Intelligent Manufacturing & $\mathrm{Xu}$ and Liu [24] \\
\hline $\begin{array}{l}\text { Advances in Intelligent and Soft } \\
\text { Computing }\end{array}$ & Huang, Zhang, and Meng [25] \\
\hline Journal of Cleaner Production & Yi et al. [26], Mohan et al. [27] \\
\hline $\begin{array}{l}\text { Journal of Advances in Management } \\
\text { Research }\end{array}$ & Nakashima and Loomba [1] \\
\hline Journal of Mechanical Design & Kwak and Kim [28] \\
\hline $\begin{array}{l}\text { Clean Technologies and } \\
\text { Environmental Policy }\end{array}$ & Yamzon et al. [29] \\
\hline Omega & Miao et al. [30] \\
\hline Applied Mathematical Modeling & Li et al. [31] \\
\hline Computers and Chemical Engineering & Zeballos et al. [32] \\
\hline
\end{tabular}

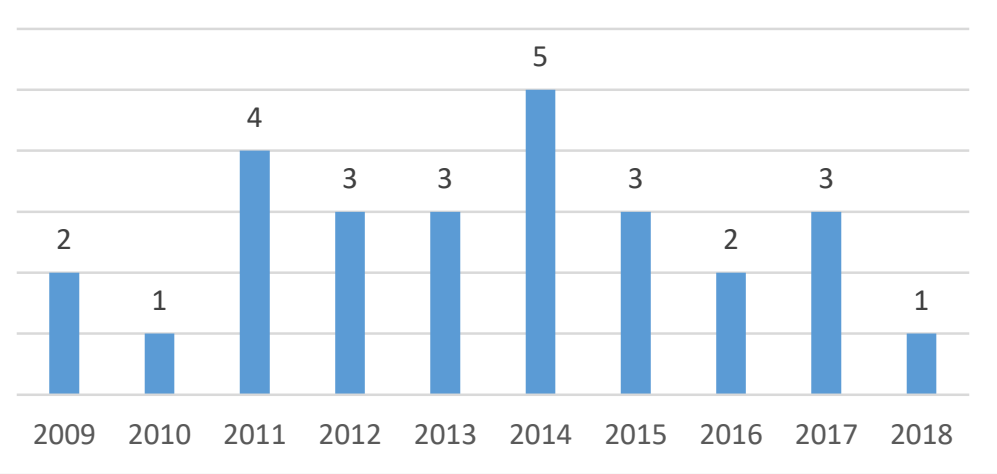

Figure 2. Literature Distribution According to Publications Period

The aforementioned 27 journal articles were printed by five reputable publishers. Publication distribution according to publishers name is presented in Figure 3. 


\section{ICATECH ITATS $=$ Thin}

The $1^{\text {st }}$ International Conference on Advanced Engineering and Technology - 2018

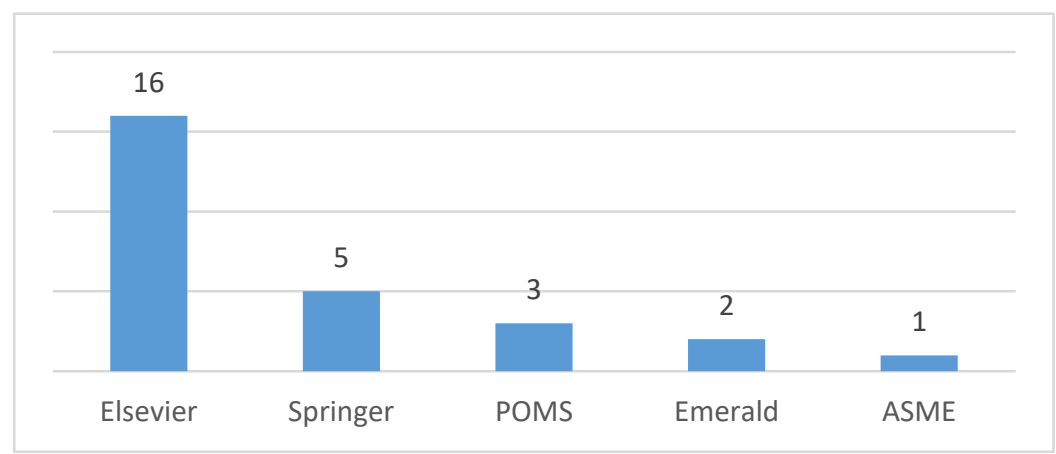

Figure 3. Literature Distribution by Publisher Name

\section{Result and Discussion}

Upon the previous review of journal articles of CLSC model, there were seven types of structural relationship between remanufacturers and consumers as raw-material suppliers [2]. Every company with limited resource ability and capacity has a distinctive pattern in managing the structural relationship. On the other hand, this literature review has identified six types of structural relationship as presented in Table 2. Ownership-Based is the one hardly ever formed in the manufacturing industry. In this type of relationship, OEM retains product ownership that they have good control over returned products. Service-Contract, like Ownership-Based, is also rarely developed in the manufacturing industry but is common in after-sales service. In this type of relationship, customers own the product, and a return is made within a set period. Deposit-Based can be a win-win solution for both customers and remanufacturers for the reason that compensation is awarded for any cores acquired. Thus, huge initial investment for cores is required. This type of relationship is suitable for high volume manufacturing.

Credit-Based encourages customers to return cores by giving proper credit. This mechanism is considered the fair deal from customers' point of view, making it possible to perform long-term collaboration. Having this type of relationship enables remanufacturers to acquire a wide variety of cores, thus requires better quality controls. Buy-Back is the most common structural relationship used in the remanufacturing industry to obtain cores with specific characteristics that are difficult to get. Lastly, Voluntary-Based is a relationship in which customers voluntarily return the cores to manufacturers. The downfall of this type of relationship is the risk of having a high supply of cores and low demand for the remanufactured product, or vice versa. 


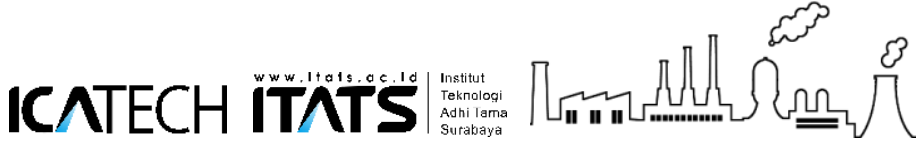

The $1^{\text {st }}$ International Conference on Advanced Engineering and Technology - 2018

Table 2. Identification of Structural Relationships and A Network Reverse Supply Chain

\begin{tabular}{|c|c|c|c|c|c|c|c|c|c|c|c|c|c|c|c|}
\hline \multirow[t]{2}{*}{ References } & \multicolumn{7}{|c|}{$\begin{array}{c}\text { Structural Relationship } \\
\text { Types }\end{array}$} & \multicolumn{4}{|c|}{ Collector } & \multicolumn{4}{|c|}{ Remanufacturer } \\
\hline & 1 & 2 & 3 & 4 & 5 & 6 & 7 & OEM & Retailer & Reman & 3PL & OEM & Retailer & Reman & 3PL \\
\hline $\begin{array}{l}\text { Qiaolun, Jianhua, } \\
\text { and Tiegang [7] }\end{array}$ & & & & & & $\sqrt{ }$ & & $\sqrt{ }$ & $\sqrt{ }$ & & $\sqrt{ }$ & $\sqrt{ }$ & & & $\sqrt{ }$ \\
\hline Maiti and Giri [8] & & & & & $\sqrt{ }$ & & & & & & $\sqrt{ }$ & $\sqrt{ }$ & & & \\
\hline Giri and Sharma [9] & & & & & $\sqrt{ }$ & & & & & & $\sqrt{ }$ & $\sqrt{ }$ & & & \\
\hline Gonsch [10] & & & & & $\sqrt{ }$ & $\sqrt{ }$ & & $\sqrt{ }$ & & $\sqrt{ }$ & & $\sqrt{ }$ & & $\sqrt{ }$ & \\
\hline $\begin{array}{l}\text { Hahler and } \\
\text { Fleischman [11] }\end{array}$ & & & & & $\sqrt{ }$ & $\sqrt{ }$ & & & & & $\sqrt{ }$ & $\sqrt{ }$ & & & \\
\hline $\begin{array}{l}\text { Aras, Gullu, and } \\
\text { Yurulmez [12] }\end{array}$ & $\sqrt{ }$ & & & & & $\sqrt{ }$ & & & & & $\sqrt{ }$ & $\sqrt{ }$ & & & \\
\hline $\begin{array}{l}\text { Kleber, Zanoni, and } \\
\text { Zavanella [13] }\end{array}$ & & $\sqrt{ }$ & & & & & & & $\sqrt{ }$ & & & $\sqrt{ }$ & $\sqrt{ }$ & & \\
\hline $\mathrm{Wu}[14]$ & & & & & & $\sqrt{ }$ & & $\sqrt{ }$ & & & & $\sqrt{ }$ & & & \\
\hline $\begin{array}{l}\text { Chuang, Wang, and } \\
\text { Zhao [15] }\end{array}$ & & & & & & $\sqrt{ }$ & & $\sqrt{1}$ & $\sqrt{ }$ & & $\sqrt{ }$ & $\sqrt{ }$ & & & \\
\hline Xiong et al. [16] & & & & & $\sqrt{ }$ & & & & & $\sqrt{ }$ & & & & $\sqrt{ }$ & \\
\hline $\begin{array}{l}\text { Wei, Tang, and Liu } \\
\text { [17] }\end{array}$ & & & & $\sqrt{ }$ & $\sqrt{ }$ & & & & $\sqrt{ }$ & & & $\sqrt{ }$ & & & \\
\hline $\begin{array}{l}\text { Bakal and Akcali } \\
{[18]}\end{array}$ & & & & & & $\sqrt{ }$ & & $\sqrt{ }$ & & & & $\sqrt{ }$ & & & \\
\hline $\begin{array}{l}\text { Galbreth and } \\
\text { Blackburn [19] }\end{array}$ & & & & & & $\sqrt{ }$ & & & & $\sqrt{ }$ & & & & $\sqrt{ }$ & \\
\hline Ferguson et al. [20] & $\sqrt{ }$ & & & & $\sqrt{ }$ & & & $\sqrt{ }$ & & & & $\sqrt{ }$ & & & \\
\hline $\begin{array}{l}\text { Feng, Govindan, } \\
\text { and Li [21] }\end{array}$ & & & & & & $\sqrt{ }$ & & & & $\sqrt{ }$ & $\sqrt{ }$ & & & $\sqrt{ }$ & $\sqrt{ }$ \\
\hline $\begin{array}{l}\text { Teunter, Douwe, } \\
\text { and Flapper [22] }\end{array}$ & & & & & $\sqrt{ }$ & & & & & & $\sqrt{ }$ & & & $\sqrt{ }$ & \\
\hline Cai et al. [23] & & & & & $\sqrt{ }$ & & & $\sqrt{ }$ & & $\sqrt{ }$ & & $\sqrt{ }$ & & $\sqrt{ }$ & \\
\hline $\mathrm{Xu}$ and Liu [24] & & & & & & $\sqrt{ }$ & & $\sqrt{ }$ & $\sqrt{ }$ & & $\sqrt{ }$ & $\sqrt{ }$ & & & \\
\hline $\begin{array}{l}\text { Huang, Zhang, and } \\
\text { Meng [25] }\end{array}$ & & & & & $\sqrt{ }$ & & & $\sqrt{ }$ & & & & $\sqrt{ }$ & & & \\
\hline Yi et al. [26] & & & & & & $\sqrt{ }$ & & & $\sqrt{ }$ & & $\sqrt{ }$ & & $\sqrt{ }$ & & \\
\hline Mohan et al. [27] & & & & & $\sqrt{ }$ & & & $\sqrt{ }$ & $\sqrt{ }$ & & $\sqrt{ }$ & $\sqrt{ }$ & & & \\
\hline $\begin{array}{l}\text { Nakashima and } \\
\text { Loomba [1] }\end{array}$ & & & & & $\sqrt{ }$ & & & & & $\sqrt{ }$ & & & & $\sqrt{ }$ & \\
\hline Kwak and Kim [28] & & & & & $\sqrt{ }$ & & $\sqrt{ }$ & & & $\sqrt{ }$ & & & & $\sqrt{ }$ & \\
\hline Yamzon et al. [29] & & & & & $\sqrt{ }$ & $\sqrt{ }$ & $\sqrt{ }$ & & $\sqrt{ }$ & & & $\sqrt{ }$ & & & \\
\hline Miao et al. [30] & & & & & $\sqrt{ }$ & & & $\sqrt{ }$ & $\sqrt{ }$ & & & $\sqrt{ }$ & & & \\
\hline Li et al. [31] & & & & & & $\sqrt{ }$ & & & & & $\sqrt{ }$ & $\sqrt{ }$ & & & \\
\hline Zeballos et al. [32] & & & & & $\sqrt{ }$ & & & & & & $\sqrt{ }$ & $\sqrt{ }$ & & & \\
\hline
\end{tabular}

The results of the systematic review of the literature confirmed that the types of structural relationship formed in a lot of remanufacturing industries are credit-based and buyback. Consumers prefer to have a credit-based relationship because they experience the fairest deal from the compensation equal to the quality of the returned product. For that reason, this system stimulates a long-term commitment between customers as the cores supplier and remanufacturers. Buy-back, on the other hand, commonly develops in remanufacturing companies due to its simple program of rewarding customers: remanufacturers immediately compensate customers during a transaction. Good relationship management with customers is essential in this type of relationship. Even though both types are more widely implemented, companies often develop more than one structural relationship at the same time.

The network structure of reverse supply chain can be identified from returned product collectors and remanufacturers. It was found that $60 \%$ of the journal articles of CLSC model investigated the single structural relationship, while the other $40 \%$ did multiple structural relationships in every possible scenario. The majority of the articles identified 3PL and OEM as the collectors and OEM as the most manufacturers. The network structure of reverse supply chain preferred by companies affects the structural relationship between customers as the cores suppliers 


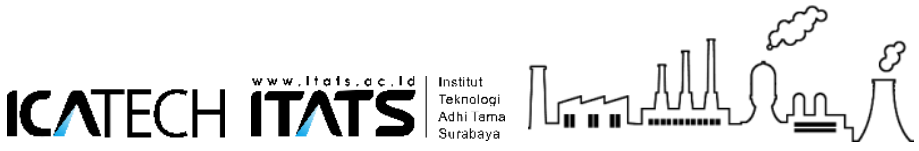

The $1^{\text {st }}$ International Conference on Advanced Engineering and Technology - 2018

and remanufacturers. The closer the relationship among supply chain players is, the more trust and commitment is built. Structural relationship management also aims at reducing risks and operational cost of the remanufacturing process, including the risks of having too many or too few cores.

\section{Conclusion}

The result of reviewing the popular journal articles issued from 2009 to 2018 confirmed that there had been an upward trend in the research of RL/CLSC. This is in accordance with the sustainability issue emerging in the global era. Twenty-seven journal articles had been classified to identify structural relationships between and or among supply chain players and reverse loop network structures of CLSC model. Upon the review, there were several structural relationships identified: ownershipbased, service-contract, deposit-based, credit-based, buy-back, and voluntary-based. Network structures of reverse supply chain determine the level of customer proximity, the level of OEM control over customers, and the risk in the process of remanufacturing operation.

In general, it can be concluded about the management of relationship among SC players for the success of remanufacturing business that: (1) structural relationship optimizes the reverse network structures coordination; (2) companies do not always develop structural relationship individually. They often implement many structural relationships. By doing so, they not only complement each other, but it can also be analyzed which the structural relationships gives the most contribution to the company. Considering the importance of structural relationship in the sustainability of remanufacturing industry, we are sure that the result of this review promotes further research. Eventually, due to personal limitations, there might be biases against the selected journal articles. Nonetheless, the presentation of this paper can benefit other researchers as a steppingstone and evaluation of the same topic area.

\section{References}

[1] K. Nakashima and A. P. S. Loomba, "Parts quality-based priority policy in remanufacturing environments," J. Adv. Manag. Res., vol. 10, no. 2, pp. 162-175, 2013.

[2] J. Östlin, E. Sundin, and M. Björkman, "Importance of closed-loop supply chain relationships for product remanufacturing," Int. J. Prod. Econ., vol. 115, no. 2, pp. 336-348, 2008.

[3] E. Sundin and O. Dunbäck, "Reverse logistics challenges in remanufacturing of automotive mechatronic devices," J. Remanufacturing, vol. 3, no. 1, p. 2, 2013.

[4] M. Ferguson and L. Toktay, "The effect of competition on recovery strategies," Prod. Oper. Manag., vol. 15, 2006.

[5] K. Govindan, H. Soleimani, and D. Kannan, "Reverse logistics and closed-loop supply chain: A comprehensive review to explore the future," Eur. J. Oper. Res., vol. 240, no. 3, pp. 603626, 2015.

[6] S. Guo, B. Shen, T. Choi, and S. Jung, "A review on supply chain contracts in reverse logistics : Supply chain structures and channel leaderships *," J. Clean. Prod., vol. 144, pp. 387-402, 2017.

[7] G. Qiaolun, J. Jianhua, and G. Tiegang, "Pricing decisions for reverse supply chains," Kybernetes, vol. 40, no. 5/6, pp. 831-841, 2011.

[8] T. Maiti and B. C. Giri, "A closed loop supply chain under retail price and product quality dependent demand," J. Manuf. Syst.

[9] B. C. Giri and S. Sharma, "Optimizing a closed-loop supply chain with manufacturing defects and quality dependent return rate," J. Manuf. Syst., vol. 35, pp. 92-111, 2015.

[10] J. Gönsch, "Buying used products for remanufacturing: negotiating or posted pricing," J. Bus. Econ., vol. 84, no. 5, pp. 715-747, 2014.

[11] S. Hahler and M. Fleischmann, "The Value of Acquisition Price Differentiation in Reverse Logistics," J. Bus. Econ., vol. 83, no. 1, pp. 1-28, 2013.

[12] N. Aras, R. Güllü, and S. Yürülmez, "Optimal inventory and pricing policies for remanufacturable leased products," Int. J. Prod. Econ., vol. 133, no. 1, pp. 262-271, 2011. 


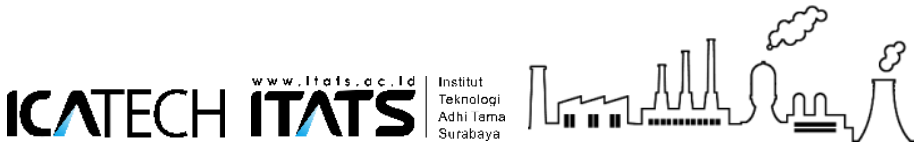

The $1^{\text {st }}$ International Conference on Advanced Engineering and Technology - 2018

[13] R. Kleber, S. Zanoni, and L. Zavanella, "Int . J . Production Economics On how buyback and remanufacturing strategies affect the profitability of spare parts supply chains," Intern. J. Prod. Econ., vol. 133, no. 1, pp. 135-142, 2011.

[14] C.-H. Wu, "Price and service competition between new and remanufactured products in a twoechelon supply chain," Int. J. Prod. Econ., vol. 140, no. 1, pp. 496-507, Nov. 2012.

[15] C. Chuang, C. X. Wang, and Y. Zhao, "Int . J . Production Economics Closed-loop supply chain models for a high-tech product under alternative reverse channel and collection cost structures," Intern. J. Prod. Econ., vol. 156, pp. 108-123, 2014.

[16] Y. Xiong, G. Li, Y. Zhou, K. Fernandes, R. Harrison, and Z. Xiong, "Dynamic pricing models for used products in remanufacturing with lost-sales and uncertain quality," Int. J. Prod. Econ., vol. 147, Part , pp. 678-688, Jan. 2014.

[17] S. Wei, O. Tang, and W. Liu, "Refund policies for coress with quality variation in OEM remanufacturing," Int. J. Prod. Econ., vol. 170, pp. 629-640, 2015.

[18] I. S. Bakal and E. Akcali, "Effects of Random Yield in Remanufacturing with Price-Sensitive Supply and Demand," Prod. Oper. Manag., vol. 15, no. 3, pp. 407-420, 2009.

[19] M. R. Galbreth and J. D. Blackburn, "Optimal acquisition quantities in remanufacturing with condition uncertainty," Prod. Oper. Manag., vol. 19, no. 1, pp. 61-69, 2010.

[20] M. Ferguson, V. D. R. Guide, K. Eylem, and G. C. Souza, "The Value of Quality Grading in Remanufacturing," 2009.

[21] L. Feng, K. Govindan, and C. Li, "Strategic planning: Design and coordination for dualrecycling channel reverse supply chain considering consumer behavior," Eur J Oper.Res., vol.260, no. 2, pp. 601-612, 2017.

[22] R. H. Teunter, S. Douwe, and P. Flapper, "Optimal cores acquisition and remanufacturing policies under uncertain cores quality fractions," Eur. J. Oper. Res., vol. 210, no. 2, pp. 241248, 2011.

[23] X. Cai, M. Lai, X. Li, Y. Li, and X. Wu, "Optimal acquisition and production policy in a hybrid manufacturing / remanufacturing system with cores acquisition at different quality levels," Eur. J. Oper. Res., vol. 233, no. 2, pp. 374-382, 2014.

[24] J. Xu and N. Liu, "Research on closed loop supply chain with reference price effect," J. Intell. Manuf., no. August, 2014.

[25] Z. Huang, G. Zhang, and L. Meng, "Research on coordination strategy of remanufacturing closed-loop supply chain based on quantity discount," Adv. Intell. Soft Comput., vol. 137 AISC, no. 2008, pp. 639-649, 2012.

[26] P. Yi, M. Huang, L. Guo, and T. Shi, "A retailer oriented closed-loop supply chain network design for end of life construction machinery remanufacturing," J. Clean. Prod., vol. 137, pp. 1393-1405, 2016.

[27] N. Mohan, N. Modak, S. Panda, and S. Sankar, "Analyzing structure of two-echelon closedloop supply chain for pricing, quality and recycling management," J. Clean. Prod., vol. 171, pp. 512-528, 2018.

[28] M. Kwak and H. Kim, "Market Positioning of Remanufactured Products With Optimal Planning for Part Upgrades," J. Mech. Des., vol. 135, no. 1, p. 011007, 2013.

[29] A. Yamzon, V. Ventura, P. Guico, and C. Sy, "Optimal planning of incentive-based quality in closed-loop supply chains," Clean Technol. Environ. Policy, no. Oecd 2011, 2016.

[30] Z. Miao, K. Fu, Z. Xia, and Y. Wang, "Models for closed-loop supply chain with trade-ins," vol. 66, pp. 308-326, 2017.

[31] J. Li, Z. Wang, B. Jiang, and T. Kim, "Coordination strategies in a three-echelon reverse supply chain for economic and social benefit R," Appl. Math. Model., vol. 49, no. 71471105, pp. 599-611, 2017.

[32] L. J. Zeballos, M. I. Gomes, A. P. Barbosa-Povoa, and A. Q. Novais, "Addressing the uncertain quality and quantity of returns in closed-loop supply chains," Comput. Chem. Eng., vol. 47, pp. 237-247, Dec. 2012. 


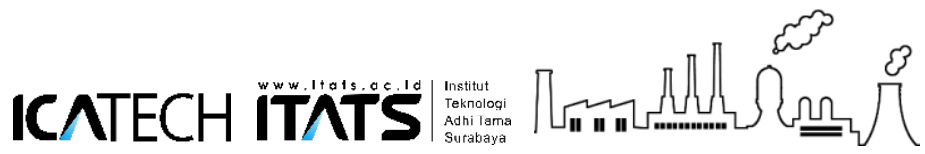

The $1^{\text {st }}$ International Conference on Advanced Engineering and Technology - 2018

\section{Acknowledgements}

The author thanked Directorate of Research and Community Service; Director General of Development and Research Enhancement; Ministry of Research, Technology, and Higher Education for funding the research on Doctoral Dissertation as stated in Research Contract's fiscal year commencing in the year 2018 Number: 35/KP/LPPM/ITATS/2018 dated March 27, 2018. 